\title{
PENETAPAN DURASI CRASH DENGAN METODE LINEAR PROGRAM UNTUK PROYEK PEMBANGUNAN BOX CULVERT NO 409 PADA JALUR KA DI DAOP 3 CIREBON
}

\author{
Dicky Arisikam ${ }^{1}$, Awan Hermawan Purwadinata ${ }^{2}$, Raden Herdian Bayu Ash Shiddiq ${ }^{3}$ \\ PT KAI (Persero) $)^{1,2}$, Universitas Widyatama ${ }^{2}$ \\ Jl. Perintis Kemerdekaan No. $1^{1,2}$, Jl. Cikutra No.204A ${ }^{2}$, Kota Bandung \\ dicky.arisikam@kai.id ${ }^{1}$, awan.hermawan@kai.id ${ }^{2}$, raden.herdian@ widyatama.ac.id $^{3}$
}

\begin{abstract}
Abstrak
Tujuan utama dari suatu proyek ialah menyelesaikan proyek tersebut sesuai dengan durasi dan biayanya. Durasi penyelesaian proyek tersebut disebut sebagai jalur kritis yang dipengaruhi oleh volume pekerjaan dan produktivitasnya.

Durasi normal proyek merupakan waktu yang diperlukan untuk menyelesaikan kegiatan dengan sumber daya yang ada (tanpa input tambahan), sedangkan normal cost merupakan biaya yang diperlukan untuk durasi normal. Data durasi normal dan normal cost umumnya diperoleh dari statistik terhadap proyek-proyek serupa yang pernah dilaksanakan. Karena adanya tujuan tertentu, durasi tersebut memungkinkan untuk dipercepat dengan input tambahan, ini disebut sebagai crash program.

Pada Proyek KA terdapat aturan bahwa pelaksanaan konstruksi tidak boleh mengganggu operasional KA apalagi sampai memberhentikan atau menutup jalur KA, sehingga Pembangunan Box Culvert No 409 harus dilaksanakan secepat mungkin. Berdasarkan statistik proyek sebelumnya, maka proyek ini direncanakan selesai dalam 92 hari kalender, namun dapat dipercepat menjadi 92 hari kalender
\end{abstract}

Kata kunci: Durasi, Crash, Box Culvert

\begin{abstract}
The main objective of the project is to complete the project in accordance with the duration and costs. The duration of the completion of the project referred to as the critical path is influenced by the volume of work and productivity.
\end{abstract}

Normal duration of a project is the time required to complete the activities with existing resources (without any extra input), while the normal cost is the cost required for the normal duration. Normal duration and cost of data obtained from statistics on similar projects before. Because of the specific objectives, the duration of allowing it to be accelerated with additional input, this is referred to as a program crash.

At the railway project there is a rule that the construction should not interfere with the operational railway and blocking the railway, so the Construction of Box Culvert No. 409 should be implemented as soon as possible. Based on statistics previous project, the project is planned for completion within 92 calendar days, but can be accelerated into 92 calendar days.

Keywords: Duration, Crash, Box Culvert

\section{Pendahuluan}

Tujuan utama dari suatu proyek ialah menyelesaikan proyek tersebut sesuai dengan durasi dan biayanya. Durasi penyelesaian proyek tersebut disebut sebagai jalur kritis yang dipengaruhi oleh volume pekerjaan dan produktivitasnya.

Durasi normal proyek merupakan waktu yang diperlukan untuk menyelesaikan kegiatan dengan sumber daya yang ada (tanpa input tambahan), sedangkan normal cost merupakan biaya yang diperlukan untuk durasi normal. Data durasi normal dan normal cost umumnya diperoleh dari statistik terhadap proyek-proyek serupa yang pernah dilaksanakan. Karena adanya tujuan tertentu, durasi tersebut memungkinkan untuk dipercepat dengan input tambahan, ini disebut sebagai crash program. 
Pada Proyek KA terdapat aturan bahwa pelaksanaan konstruksi tidak boleh mengganggu operasional KA apalagi sampai memberhentikan atau menutup jalur KA, sehingga Pembangunan Box Culvert No 409 harus dilaksanakan secepat mungkin. Berdasarkan statistik proyek sebelumnya, maka proyek ini direncanakan selesai dalam 120 hari kalender, namun karena pertimbangan operasional KA, maka proyek tersebut akan dipercepat se-optimal mungkin yang dianalisis dengan menggunakan metode linear program.

\section{KAJIAN LITERATUR}

Menurut Mulyono (2004), pemrograman linier (linear programming, disingkat LP) Merupakan salah satu teknik penelitian bedah yang paling banyak digunakan, bagus. Pemrograman linier adalah metode matematika untuk mengalokasikan sumber daya yang langka. Untuk mencapai tujuan. Pemrograman linier adalah metode matematika Dirancang untuk membantu manajer operasi dalam perencanaan dan pengambilan keputusan Sumber daya harus dialokasikan berdasarkan pendapat Heizer dan Render (2006). Pemrograman linier mewakili penggunaan teknik matematika tertentu untuk melakukan hal berikut: Solusi terbaik untuk masalah terbatas sumber daya. Pemrograman linier Apakah salah satu cara untuk memecahkan masalah alokasi sumber daya di Selama kegiatan bersaing dengan cara yang terbaik. Linear progamming merupakan suatu teknik yang membantu pengambilan keputusan dalam mengalokasikan sumber daya (mesin, tenaga kerja, uang, waktu, kapasitas gudang, dan bahan baku). Linear programming merupakan penggunaan secara luas dari teknik model matematika yang dirancang untuk membantu manajer dalam merencanakan dan mengambil keputusan dalam mengalokasikan sumber daya.

Tujuan dari kajian ini ialah (1) Untuk mengetahui network dari Proyek Pembangunan Box Culvert No 409 dengan menggunkan analisis Critical Path Method (CPM), (2) Untuk mengetahui durasi normal penyelesaian proyek tersebut (jalur kritis normal), (3) Untuk mengetahui durasi crash yang paling mungkin untuk menyelesaikan proyek tersebut (jalur kritis crash).

Adapun ruang lingkup pada kajian ini adalah (1) Kajian dilakukan Proyek Pembangunan Box Culvert Kereta Api No 409 antara Telagasari - Jatibarang Koridor Cikampek - Cirebon. (2) Penentuan durasi setiap kegiatan menggunakan PDF Beta berdasarkan pengalaman Penulis dalam mengerjakan proyek serupa. (3) Penentuan durasi normal (jalur kritis) menggunakan Critical Path Method (CPM). (4) Penentuan durasi crash dengan metode linear program dan bantuan Software $Q M$ untuk penyelesaiannya. (5) Kajian ini tidak memperhitungkan biaya dan sumber daya pelaksanaan proyek, tetapi hanya fokus pada durasi pekerjaan saja.

\section{Analisis dan Perancangan}

Secara umum metodologi pada kajian ini antara lain :

a. Studi literatur.

b. Mengumpulkan data terkait proyek tersebut.

c. Menentukan durasi setiap kegiatan dengan menggunakan PDF Beta berdasarkan pengalaman Penulis dalam mengerjakan proyek serupa.

d. Menentukan durasi normal (jalur kritis) dengan membuat Critical Path Method (CPM).

e. Menentukan persamaan linear untuk menghitung crash program.

f. Menghitung crash program dengan bantuan Software QM.

\section{III.1 Data}

Tabel 1. BQ Pekerjaan Box Culvert No 409

\begin{tabular}{|c|r|r|l|}
\hline NO & \multicolumn{1}{|c|}{ VOL } & SAT & \multicolumn{1}{|c|}{ URAIAN PEKERJAAN } \\
\hline & & & I. PEKERJAAN PERSIAPAN : \\
\hline A & 1,00 & ls & Mobilisasi alat dan material \\
\hline B & 1,00 & ls & Pembersihan lokasi pekerjaan \\
\hline C & 12,00 & $\mathrm{~m} 2$ & Membuat direksikeet dan gudang material \\
\hline & & & II. PEKERJAAN PELAKSANAAN : \\
\hline D & 3,00 & jlr & Pasang rel bendel untuk pengaku track \\
\hline E & 7,00 & $\mathrm{~m} 3$ & Bongkar ballast diganti stapling \\
\hline F & 16,00 & $\mathrm{~m} 2$ & Pasang gambangan \\
\hline G & 6,00 & ton & Pasang baja pemikul sementara \\
\hline H & 4,00 & $\mathrm{~m}$ & Pasang kisdam \\
\hline I & 30,00 & $\mathrm{~m} 3$ & Galian tanah biasa \\
\hline J & 9,00 & $\mathrm{~m} 3$ & Bongkar pasangan batu kali eksisting \\
\hline K & 0,95 & $\mathrm{~m} 3$ & Cor lantai kerja \\
\hline L & 40,00 & $\mathrm{~m} 2$ & Pasang bekisting \\
\hline M & $1.333,00$ & $\mathrm{~kg}$ & Penulangan \\
\hline N & 9,40 & $\mathrm{~m} 3$ & Cor beton struktur \\
\hline O & 40,00 & $\mathrm{~m} 2$ & Bongkar bekisting setelah beton mengeras \\
\hline P & 8,00 & $\mathrm{~m} 3$ & Pasang batu kali untuk talud \\
\hline Q & 17,00 & $\mathrm{~m} 2$ & Mengerjakan plesteran \\
\hline R & 1,00 & ls & $\begin{array}{l}\text { Bongkar rel bendel, stapling, gambangan, } \\
\text { baja pemikul, kisdam }\end{array}$ \\
\hline S & 10,50 & $\mathrm{~m} 3$ & Masukan ballast termasuk bahan \\
\hline T & 40,00 & $\mathrm{~m}$ 'sp & Angkat listring track \\
\hline & & & III. PEKERJAAN PENYELESAIAN \\
\hline U & 12,00 & $\mathrm{~m} 2$ & Bongkar direksikeet dan gudang kerja \\
\hline V & 1,00 & ls & Finishing dan pembersihan lokasi \\
\hline W & 1,00 & ls & Demobilisasi \\
\hline & & & \\
\hline
\end{tabular}

Sumber: Data PT KAI

Dicky Arisikam, Awan Hermawan Purwadinata, Raden Herdian Bayu Ash Shiddiq 


\section{III.2 Penentuan Durasi dengan PDF Beta}

Penetuan durasi setiap kegiatan pada Proyek Pembangunan Box Culvert No 409 antara Telagasari - Jatibarang Koridor Cikampek - Cirebon dengan menggunakan PDF Beta yang dilakukan berdasarkan pengalaman Penulis dalam mengerjakan proyek serupa sebelumnya.

Tabel 2. Penentuan Durasi Normal

\begin{tabular}{|c|c|c|c|c|}
\hline NO & $\begin{array}{c}\text { URAIAN } \\
\text { PEKERJAAN }\end{array}$ & $\begin{array}{c}\text { KEG } \\
\text { SEBELUM }\end{array}$ & $\begin{array}{c}\text { KEG } \\
\text { SETELAH }\end{array}$ & $\begin{array}{c}\text { PDF } \\
\text { BETA }\end{array}$ \\
\hline & \multicolumn{4}{|c|}{ I. PEKERJAAN PERSIAPAN : } \\
\hline A & \begin{tabular}{|l} 
Mobilisasi alat dan \\
material
\end{tabular} & - & $\mathrm{B}, \mathrm{C}$ & $1,2,3$ \\
\hline B & $\begin{array}{l}\text { Pembersihan lokasi } \\
\text { pekerjaan }\end{array}$ & A & $\mathrm{D}, \mathrm{H}$ & $1,2,3$ \\
\hline \multirow[t]{2}{*}{$\mathrm{C}$} & $\begin{array}{l}\text { Membuat direksikeet } \\
\text { dan gudang material }\end{array}$ & A & $\mathrm{D}, \mathrm{H}$ & $2,3,4$ \\
\hline & \multicolumn{4}{|c|}{ II. PEKERJAAN PELAKSANAAN : } \\
\hline $\mathrm{D}$ & $\begin{array}{l}\text { Pasang rel bendel } \\
\text { untuk pengaku track }\end{array}$ & $\mathrm{B}, \mathrm{C}$ & $\mathrm{E}, \mathrm{F}$ & $1,2,3$ \\
\hline $\mathrm{E}$ & $\begin{array}{l}\text { Bongkar ballast } \\
\text { diganti stapling }\end{array}$ & $\mathrm{D}$ & G & $1,2,3$ \\
\hline $\mathrm{F}$ & Pasang gambangan & $\mathrm{D}$ & G & $1,2,3$ \\
\hline G & $\begin{array}{l}\text { Pasang baja pemikul } \\
\text { sementara }\end{array}$ & E, F & $\mathrm{I}, \mathrm{J}$ & $2,3,4$ \\
\hline $\mathrm{H}$ & Pasang kisdam & $\mathrm{B}, \mathrm{C}$ & $\mathrm{I}, \mathrm{J}$ & $1,2,3$ \\
\hline $\mathrm{I}$ & Galian tanah biasa & $\mathrm{G}, \mathrm{H}$ & $\mathrm{K}$ & $3,4,5$ \\
\hline $\mathrm{J}$ & $\begin{array}{l}\text { Bongkar pasangan } \\
\text { batu kali eksisting }\end{array}$ & $\mathrm{G}, \mathrm{H}$ & $\mathrm{K}$ & $2,3,4$ \\
\hline $\mathrm{K}$ & Cor lantai kerja & $\mathrm{I}, \mathrm{J}$ & $\mathrm{L}$ & $4,5,6$ \\
\hline $\mathrm{L}$ & Pasang bekisting & $\mathrm{K}$ & $\mathrm{M}$ & $4,5,6$ \\
\hline $\mathrm{M}$ & Penulangan & $\mathrm{L}$ & $\mathrm{N}$ & $6,8,11$ \\
\hline $\mathrm{N}$ & Cor beton struktur & $\mathrm{M}$ & $\mathrm{O}$ & $35,36,38$ \\
\hline $\mathrm{O}$ & $\begin{array}{l}\text { Bongkar bekisting } \\
\text { setelah beton } \\
\text { mengeras }\end{array}$ & $\mathrm{N}$ & $\mathrm{P}, \mathrm{Q}$ & $1,2,3$ \\
\hline $\mathrm{P}$ & $\begin{array}{l}\text { Pasang batu kali } \\
\text { untuk talud }\end{array}$ & $\mathrm{O}$ & $\mathrm{R}$ & $3,4,5$ \\
\hline Q & $\begin{array}{l}\text { Mengerjakan } \\
\text { plesteran }\end{array}$ & $\mathrm{O}$ & $\mathrm{U}$ & $2,3,4$ \\
\hline $\mathrm{R}$ & $\begin{array}{l}\text { Bongkar rel bendel, } \\
\text { stapling, gambangan, } \\
\text { baja pemikul, } \\
\text { kisdam }\end{array}$ & $\mathrm{P}$ & $\mathrm{S}$ & $1,2,3$ \\
\hline $\mathrm{S}$ & $\begin{array}{l}\text { Masukan ballast } \\
\text { termasuk bahan }\end{array}$ & $\mathrm{R}$ & $\mathrm{T}$ & $3,4,5$ \\
\hline \multirow[t]{2}{*}{$\mathrm{T}$} & Angkat listring track & $\mathrm{S}$ & $\mathrm{U}$ & $3,4,5$ \\
\hline & \multicolumn{4}{|c|}{ III. PEKERJAAN PENYELESAIAN } \\
\hline $\bar{U}$ & $\begin{array}{l}\text { Bongkar direksikeet } \\
\text { dan gudang kerja }\end{array}$ & Q, T & $\mathrm{V}$ & $1,2,3$ \\
\hline $\mathrm{V}$ & $\begin{array}{l}\text { Finishing dan } \\
\text { pembersihan lokasi }\end{array}$ & $\mathrm{U}$ & $\mathrm{W}$ & $1,2,3$ \\
\hline $\mathrm{W}$ & Demobilisasi & V & - & $1,2,3$ \\
\hline
\end{tabular}

\section{Sumber: Data PT KAI}

\section{III.3 Penentuan Jalur Kritis Dengan Critical Path Method (CPM)}

Berdasarkan data pada Tabel 2 diatas maka dapat dibuatkan Critical Path Method (CPM) untuk menentukan durasi normal penyelesaian proyek tersebut (jalur kritis) sebagai berikut.
Jalur kritis $=\mathrm{A}-\mathrm{C}-\mathrm{D}-\mathrm{E}-\mathrm{G}-\mathrm{I}-\mathrm{K}-\mathrm{L}-\mathrm{M}-\mathrm{N}-$ $\mathrm{O}-\mathrm{P}-\mathrm{R}-\mathrm{S}-\mathrm{T}-\mathrm{U}-\mathrm{V}-\mathrm{W}$.

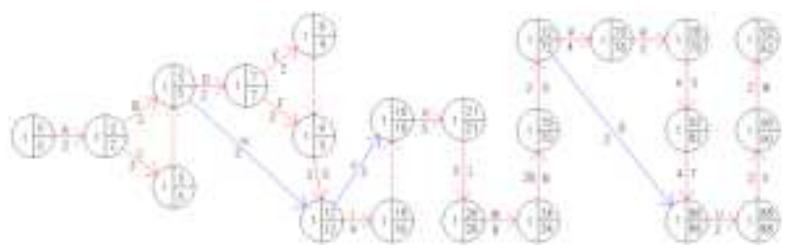

Gambar 1. Diagram CPM

\section{III.4 Penentuan Durasi Crash Setiap Kegiatan}

Tabel 3. Penentuan Durasi Crash

\begin{tabular}{|c|c|c|c|c|}
\hline NO & $\begin{array}{c}\text { URAIAN } \\
\text { PEKERJAAN }\end{array}$ & $\begin{array}{l}\text { DURASI } \\
\text { CRASH }\end{array}$ & $\begin{array}{c}\text { DURASI } \\
\text { NORMAL }\end{array}$ & $\begin{array}{l}\text { PDF } \\
\text { BETA }\end{array}$ \\
\hline & \multicolumn{4}{|c|}{ I. PEKERJAAN PERSIAPAN : } \\
\hline A & $\begin{array}{l}\text { Mobilisasi alat dan } \\
\text { material }\end{array}$ & 1 & 2 & $1,2,3$ \\
\hline B & $\begin{array}{l}\text { Pembersihan lokasi } \\
\text { pekerjaan }\end{array}$ & 1 & 2 & $1,2,3$ \\
\hline \multirow[t]{2}{*}{$\mathrm{C}$} & $\begin{array}{l}\text { Membuat direksikeet } \\
\text { dan gudang material }\end{array}$ & 2 & 3 & $2,3,4$ \\
\hline & \multicolumn{4}{|c|}{ II. PEKERJAAN PELAKSANAAN : } \\
\hline $\mathrm{D}$ & $\begin{array}{l}\text { Pasang rel bendel } \\
\text { untuk pengaku track }\end{array}$ & 1 & 2 & $1,2,3$ \\
\hline $\mathrm{E}$ & $\begin{array}{l}\text { Bongkar ballast } \\
\text { diganti stapling }\end{array}$ & 1 & 2 & $1,2,3$ \\
\hline $\mathrm{F}$ & Pasang gambangan & 1 & 2 & $1,2,3$ \\
\hline G & $\begin{array}{l}\text { Pasang baja pemikul } \\
\text { sementara }\end{array}$ & 2 & 3 & $2,3,4$ \\
\hline $\mathrm{H}$ & Pasang kisdam & 1 & 2 & $1,2,3$ \\
\hline $\mathrm{I}$ & Galian tanah biasa & 3 & 4 & $3,4,5$ \\
\hline $\mathbf{J}$ & $\begin{array}{l}\text { Bongkar pasangan } \\
\text { batu kali eksisting } \\
\end{array}$ & 2 & 3 & $2,3,4$ \\
\hline $\mathrm{K}$ & Cor lantai kerja & 4 & 5 & $4,5,6$ \\
\hline $\mathrm{L}$ & Pasang bekisting & 4 & 5 & $4,5,6$ \\
\hline $\mathrm{M}$ & Penulangan & 6 & 8 & $6,8,11$ \\
\hline $\mathrm{N}$ & Cor beton struktur & 35 & 36 & $35,36,38$ \\
\hline $\mathrm{O}$ & $\begin{array}{l}\text { Bongkar bekisting } \\
\text { setelah beton } \\
\text { mengeras } \\
\end{array}$ & 1 & 2 & $1,2,3$ \\
\hline $\mathrm{P}$ & $\begin{array}{l}\text { Pasang batu kali } \\
\text { untuk talud }\end{array}$ & 3 & 4 & $3,4,5$ \\
\hline Q & $\begin{array}{l}\text { Mengerjakan } \\
\text { plesteran }\end{array}$ & 2 & 3 & $2,3,4$ \\
\hline $\mathrm{R}$ & $\begin{array}{l}\text { Bongkar rel bendel, } \\
\text { stapling, gambangan, } \\
\text { baja pemikul, } \\
\text { kisdam }\end{array}$ & 1 & 2 & $1,2,3$ \\
\hline $\mathrm{S}$ & $\begin{array}{l}\text { Masukan ballast } \\
\text { termasuk bahan }\end{array}$ & 3 & 4 & $3,4,5$ \\
\hline \multirow[t]{2}{*}{$\mathrm{T}$} & Angkat listring track & 3 & 4 & $3,4,5$ \\
\hline & \multicolumn{4}{|c|}{ III. PEKERJAAN PENYELESAIAN } \\
\hline $\mathrm{U}$ & $\begin{array}{l}\text { Bongkar direksikeet } \\
\text { dan gudang kerja }\end{array}$ & 1 & 2 & $1,2,3$ \\
\hline $\mathrm{V}$ & $\begin{array}{l}\text { Finishing dan } \\
\text { pembersihan lokasi }\end{array}$ & 1 & 2 & $1,2,3$ \\
\hline $\mathrm{W}$ & Demobilisasi & 1 & 2 & $1,2,3$ \\
\hline
\end{tabular}

Sumber: Data PT KAI

\section{III.5 Linear Program}

1. Variabel keputusan :

$\mathrm{Xa} \quad \rightarrow$ berapa lama kegiatan A perlu di crash

$\mathrm{Xb} \quad \rightarrow$ berapa lama kegiatan B perlu di crash

Dicky Arisikam, Awan Hermawan Purwadinata, Raden Herdian Bayu Ash Shiddiq 
$\mathrm{Xc} \rightarrow$ berapa lama kegiatan $\mathrm{C}$ perlu di crash

$\mathrm{Xd} \quad \rightarrow$ berapa lama kegiatan D perlu di crash

$\mathrm{Xe} \quad \rightarrow$ berapa lama kegiatan E perlu di crash

$\mathrm{Xf} \quad \rightarrow$ berapa lama kegiatan F perlu di crash

$\mathrm{Xg} \rightarrow$ berapa lama kegiatan $\mathrm{G}$ perlu di crash

$\mathrm{Xh} \quad \rightarrow$ berapa lama kegiatan $\mathrm{H}$ perlu di crash

$\mathrm{Xi} \quad \rightarrow$ berapa lama kegiatan I perlu di crash

$\mathrm{Xj} \quad \rightarrow$ berapa lama kegiatan J perlu di crash

$\mathrm{Xk} \quad \rightarrow$ berapa lama kegiatan K perlu di crash

$\mathrm{Xl} \quad \rightarrow$ berapa lama kegiatan L perlu di crash

$\mathrm{Xm} \rightarrow$ berapa lama kegiatan M perlu di crash

$\mathrm{Xn} \quad \rightarrow$ berapa lama kegiatan $\mathrm{N}$ perlu di crash

Xo $\quad \rightarrow$ berapa lama kegiatan O perlu di crash

$\mathrm{Xp} \quad \rightarrow$ berapa lama kegiatan P perlu di crash

$\mathrm{Xq} \quad \rightarrow$ berapa lama kegiatan Q perlu di crash

$\mathrm{Xr} \quad \rightarrow$ berapa lama kegiatan R perlu di crash

$\mathrm{Xs} \quad \rightarrow$ berapa lama kegiatan $\mathrm{S}$ perlu di crash

$\mathrm{Xt} \quad \rightarrow$ berapa lama kegiatan T perlu di crash

$\mathrm{Xu} \quad \rightarrow$ berapa lama kegiatan U perlu di crash

$\mathrm{Xv} \quad \rightarrow$ berapa lama kegiatan V perlu di crash

$\mathrm{Xw} \rightarrow$ berapa lama kegiatan $\mathrm{W}$ perlu di crash

Fungsi tujuan, untuk meminimumkan jumlah penambahan biaya :

$$
\begin{aligned}
\mathrm{Z}= & (\mathrm{Ca} \times \mathrm{Xa})+(\mathrm{Cb} \times \mathrm{Xb})+(\mathrm{Cc} \times \mathrm{Xc})+ \\
& (\mathrm{Cd} \times \mathrm{Xd})+(\mathrm{Ce} \times \mathrm{Xe})+(\mathrm{Cf} \times \mathrm{Xf})+ \\
& (\mathrm{Cg} \times \mathrm{Xg})+(\mathrm{Ch} \times \mathrm{Xh})+(\mathrm{Ci} \times \mathrm{Xi})+ \\
& (\mathrm{Cj} \times \mathrm{Xj})+(\mathrm{Ck} \times \mathrm{Xk})+(\mathrm{Cl} \times \mathrm{Xl})+ \\
& (\mathrm{Cm} \times \mathrm{Xm})+(\mathrm{Cn} \times \mathrm{Xn})+(\mathrm{Co} \times \mathrm{Xo})+ \\
& (\mathrm{Cp} \times \mathrm{Xp})+(\mathrm{Cq} \times \mathrm{Xq})+(\mathrm{Cr} \times \mathrm{Xr})+ \\
& (\mathrm{Cs} \times \mathrm{Xs})+(\mathrm{Ct} \times \mathrm{Xt})+(\mathrm{Cu} \times \mathrm{Xu})+ \\
& (\mathrm{Cv} \times \mathrm{Xv})+(\mathrm{Cw} \times \mathrm{Xw})
\end{aligned}
$$

$\mathrm{Ca}, \mathrm{Cb}, \ldots \ldots . . \mathrm{Cw} \rightarrow$ Cost Slope kegiatan A sd $\mathrm{W}$

$\mathrm{Ca}, \mathrm{Cb}, \ldots \ldots . ., \mathrm{Cw} \rightarrow$ dianggap 1 (parameter biaya diabaikan)

Batas maksimum pemendekan :

$\begin{array}{llll}\mathrm{Xa} & \leq 2-1=1 & \mathrm{Xm} & \leq 8-6=2 \\ \mathrm{Xb} & \leq 2-1=1 & \mathrm{Xn} & \leq 36-35=1 \\ \mathrm{Xc} & \leq 3-2=1 & \mathrm{Xo} & \leq 2-1=1 \\ \mathrm{Xd} & \leq 2-1=1 & \mathrm{Xp} & \leq 4-3=1 \\ \mathrm{Xe} & \leq 2-1=1 & \mathrm{Xq} & \leq 3-2=1 \\ \mathrm{Xf} & \leq 2-1=1 & \mathrm{Xr} & \leq 2-1=1 \\ \mathrm{Xg} & \leq 3-2=1 & \mathrm{Xs} & \leq 4-3=1 \\ \mathrm{Xh} & \leq 2-1=1 & \mathrm{Xt} & \leq 4-3=1 \\ \mathrm{Xi} & \leq 4-3=1 & \mathrm{Xu} & \leq 2-1=1 \\ \mathrm{Xj} & \leq 3-2=1 & \mathrm{Xv} & \leq 2-1=1 \\ \mathrm{Xk} & \leq 5-4=1 & \mathrm{Xw} & \leq 2-1=1 \\ \mathrm{Xl} & \leq 5-4=1 & & \end{array}$

Target pemendekan :

Pekerjaan tersebut diharapkan dapat selesai dalam 85 hari kalender (dipercepat 1 minggu), sehingga target pemendekan adalah 7 hari, maka persamaan linear menjadi :

$\mathrm{Xa}+\mathrm{Xc}+\mathrm{Xd}+\mathrm{Xe}+\mathrm{Xg}+\mathrm{Xi}+\mathrm{Xk}+\mathrm{Xl}+\mathrm{Xm}+$ $\mathrm{Xn}+\mathrm{Xo}+\mathrm{Xp}+\mathrm{Xr}+\mathrm{Xs}+\mathrm{Xt}+\mathrm{Xu}+\mathrm{Xv}+\mathrm{Xw}=$ 7

\section{III.6 Software QM}

Dengan menggunakan bantuan Software QM, maka persamaan linear program tersebut dapat diselesaikan sebagai berikut.

Kendala program linear, agar nilainya positif :

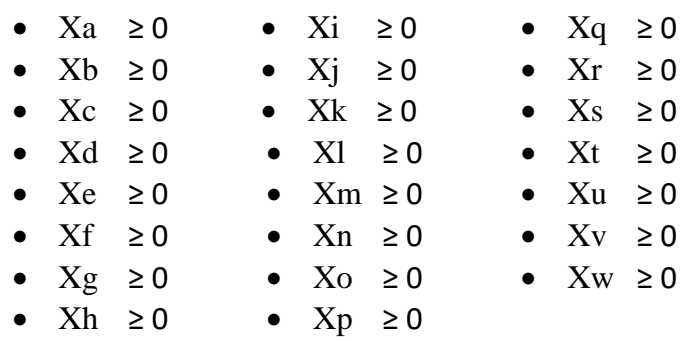

Kendala loop, diperlukan agar jalur kritis tidak pindah

- $X d+X e+X g \geq X h$

$X d+X e+X g-X h \geq 5$

- $X i \geq X j$

$X i-X j \geq 1$

- $X p+X r+X s+X t \geq X q$

$X p+X r+X s+X t-X q \geq 11$

\section{KESIMPULAN DAN SARAN}

Pada Proyek KA terdapat aturan bahwa pelaksanaan konstruksi tidak boleh mengganggu operasional KA apalagi sampai memberhentikan atau menutup jalur KA, sehingga Pembangunan Box Culvert No 409 harus dilaksanakan secepat mungkin. Berdasarkan statistik proyek sebelumnya, maka proyek ini direncanakan selesai dalam 92 hari kalender, namun dapat dipercepat menjadi 92 hari kalender.

\section{REFERENSI}

Sumardi, Biemo W, 2015, "Bahan Kuliah SI-5101 Analisa Rekayasa 1", Tidak Dipublikasikan, Institut Teknologi Bandung. 
Tamin, Rizal Z, 2015, "Bahan Kuliah SI-5152 Sistem Perencanaan dan Pengendalian Proyek", Tidak Dipublikasikan, Institut Teknologi Bandung.

Render, Barry, Ralph M. Stair, Michael E. Hanna, 2012, "Quantitative Analysis For Management", New York : Pearson Education, Inc. 